\title{
Ambiente acadêmico brasileiro: branquidade e exclusão de direitos dos estudantes negros ${ }^{1}$
}

\author{
Brazilian academic environment: whiteness and the \\ exclusion of Black Students Rights
}

\section{Ambiente académico brasileño: blanquitud y exclusión de los derechos de los estudiantes negros}

\author{
iD Sales Augusto dos Santos \\ Universidade Federal de Viçosa, Viçosa, Minas Gerais, Brasil \\ salesaugustodossantos@gmail.com
}

Resumo: O presente artigo visa a compreender por que os membros do Conselho de Ensino, Pesquisa e Extensão (CEPE) da Universidade Federal de Viçosa (UFV) impuseram uma forma de operacionalização à Comissão de Verificação de Autodeclaração Étnico-Racial (CVAER) da instituição que, simultânea e contraditoriamente, impediu o ingresso fraudulento de alguns estudantes brancos nas vagas das subcotas étnico-raciais destinadas aos estudantes pretos, pardos e indígenas, que era o objetivo da referida comissão, mas também permitiu o ingresso de dezenas de estudantes brancos nessas vagas. Por meio de fatos, dados e argumentos consistentes e plausíveis, sustenta-se a hipótese de que a tomada de decisão dos membros do CEPE foi em virtude da branquidade, isto é, do privilégio racial (branco) dos conselheiros desse órgão da universidade.

Palavras-Chave: Universidade. Branquidade. Ação Afirmativa. Heteroidentificação Étnico-Racial. Comissões de Verificação.

1 Somos gratos aos comentários, sugestões e críticas da professora Georgina Helena Lima Nunes e dos/as pareceristas do artigo. Contudo, qualquer erro ou equívoco é de inteira responsabilidade do autor deste artigo. 
Abstract: This article aims to understand why the members of the Teaching, Research and Extension Council (CEPE) of the Universidade Federal de Viçosa (UFV) have imposed a form of operationalization to the Ethnic-Racial Self-declaration Verification Commission (CVAER) of the institution, which, simultaneous and contradictorily, on the one hand, it prevented some white students from fraudulently entering the ethnicracial sub-quotas for black, brown, and indigenous students, which was the goal of the commission, but on the other hand, it allowed dozens of white students to enter ethnic-racial sub-quotas spots. Relying on data and theory-driven arguments we presented the hypothesis that the decision-making of the CEPE commission members was due to whiteness, that is, the white racial privilege of the CEPE advisors of the UFV.

Keywords: University. Whiteness. Affirmative Action. Ethnic-Racial Heteroidentification. Verification Commission.

Resumen: En este artículo tiene como objetivo comprender por qué los miembros del Consejo de Enseñanza, Investigación y Extensión (CEPE) de la Universidade Federal de Viçosa (UFV) han impuesto a la Comisión de Verificación de Autodeclaraciones Étnico-Raciales (CVAER) de la institución una forma de operar que, simultánea y contradictoriamente, impidió que algunos estudiantes blancos ingresaran fraudulentamente en los cupos reservados a las subcuotas étnico-raciales destinadas a estudiantes negros, pardos e indígenas, pero también permitió que decenas de estudiantes blancos ingresaran a estos cupos. Apoyándose en datos y argumentos teóricos se presenta la hipótesis de que la toma de decisiones de los miembros de la comisión CEPE se debió a la blanquitud, es decir, al privilegio racial (blanco) de los miembros del CEPE de la UFV.

Palabras clave: Universidad. Blanquitud. Acción Afirmativa, Heteroidentificación Étnico-racial. Comisión de Verificación.

Data de recebimento: 26/09/2020

Data de aprovação: 27/08/2021 
Ambiente acadêmico brasileiro: branquidade e exclusão de direitos dos estudantes negros

\section{Introdução}

Em dois artigos publicados no ano de 2019, os cientistas sociais Santos e Freitas (2019a e 2019b)² analisaram o processo de implementação do sistema de cotas da UFV, para estudantes oriundos de escolas públicas, conforme implementação determinada pela Lei Federal $n^{\circ} 12.711 / 2012$, a chamada Lei das Cotas. No primeiro artigo, Santos e Freitas (2019a) analisaram a presença, bem como o impacto e a repercussão do ingresso de estudantes pretos e pardos na Universidade Federal de Viçosa (UFV), por meio das subcotas étnico-raciais, em seis cursos que são considerados de alto prestígio na universidade: Agronomia, Direito, Engenharia Mecânica, Engenharia Química, Medicina e Medicina Veterinária. Entre outros resultados, os autores constataram que houve baixo ingresso de estudantes (mulheres) pretas nesses cursos, em razão de fraudes praticadas por estudantes brancos nessas subcotas.

Segundo Santos e Freitas (2019a), as fraudes foram denunciadas pelos movimentos negros da cidade de Viçosa-MG e por estudantes negros (pretos e pardos) da própria UFV, o que pressionou a instituição a tentar resolver o problema, isto é, tentar impedi-lo. Dessa forma, a universidade criou, em março de 2017, a Comissão de Verificação de Autodeclaração Étnico-Racial (CVAER)³, para convocar e heteroidentificar alunos brancos que foram denunciados à instituição por fraudar as subcotas étnico-raciais destinadas aos estudantes pretos, pardos e indígenas.

Contudo, apesar da implantação e do funcionamento da CVAER, as fraudes continuaram sendo praticadas. Em razão disso, os pesquisadores, dando continuidade à primeira pesquisa, realizaram a segunda investigação (SANTOS e FREITAS, 2019b), visando a verificar o modus operandi da CVAER e, consequentemente, aferir a sua eficiência na averiguação e impedimento das fraudes

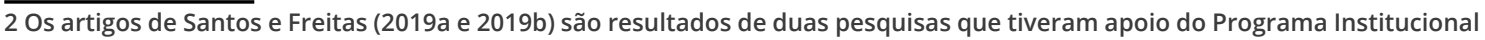
de Bolsas de Iniciação Científica (PIBIC), Editais 2017/2018 e 2018/2019, financiados pelo Conselho Nacional de Desenvolvimento Científico e Tecnológico (CNPq).

3 À época a comissão tinha seis membros efetivos e seis suplentes, sendo, respectivamente, dois professores, dois servidores técnicos administrativos, um estudante de graduação e um estudante de pós-graduação (BRASIL, 2017b). 
Ambiente acadêmico brasileiro: branquidade e exclusão de direitos dos estudantes negros Sales Augusto dos Santos

praticadas por estudantes brancos nas subcotas étnico-raciais. Entre outros resultados, Santos e Freitas (2019b) concluíram que a CVAER conseguiu coibir fraudes, que era seu objetivo primeiro. Porém, contraditória e simultaneamente, a CVAER foi um locus para a legitimação desse crime, em face de uma imposição do Conselho de Ensino, Pesquisa e Extensão (CEPE) da universidade à sua atuação, deliberada na reunião do dia 08 de março de 2017 desse conselho, qual seja, de que "o estudante [denunciado como fraudador das subcotas étnico-raciais] será considerado não enquadrado na condição de pessoa preta, parda ou indígena quando houver unanimidade entre os integrantes da Comissão" (BRASIL, 2017a).

Assim, recorrendo a um argumento muito utilizado no meio jurídico, in dubio pro reo, os membros do CEPE estabeleceram que os estudantes acusados de fraudadores não seriam identificados e/ou constatados por meio da maioria dos votos dos membros da CVAER da UFV, mas somente pelos votos de todos os seus membros, ou seja, por unanimidade dos votos dos membros da CVAER. Por exemplo, se quatro dos cinco membros da comissão heteroidentificassem como branco um aluno acusado de fraudar as subcotas étnico-raciais, mas apenas um de seus membros o heteroidentificasse como pardo ou preto ou indígena, esse estudante não seria considerado fraudador das subcotas étnico-raciais. Ao contrário, ele seria heteroidentificado como pardo, ou preto ou indígena, logo, seria considerado sujeito de direito das subcotas e ingressaria em uma de suas vagas.

Santos e Freitas (2019b) demonstraram por meio de dados e argumentos consistentes que a utilização do argumento in dubio pro reo para fundamentar a imposição supracitada era insustentável de uma perspectiva racional, assim como evidenciaram que essa fundamentação foi um dos principais fatores para excluir da UFV dezenas de estudantes negros e indígenas, que eram os reais sujeitos de direito das subcotas étnico-raciais, e, simultaneamente incluir dezenas de estudantes brancos na universidade, que não 
Ambiente acadêmico brasileiro: branquidade e exclusão de direitos dos estudantes negros Sales Augusto dos Santos

eram e não poderiam ser beneficiários das subcotas conforme a Lei $n^{\circ} 12.711 / 2012$.

Todavia, apesar de os sociólogos Santos e Freitas (2019a e 2019b) realizarem pesquisas meticulosas e convincentes acadêmico-cientificamente, mostrando falhas gritantes e injustificáveis no processo de correção da implementação das subcotas étnico-raciais da UFV, eles não focaram responder por que os conselheiros do CEPE deliberaram a imposição supracitada à CVAER da UFV. Eis aí o que vamos analisar neste artigo. A resposta à questão supracitada pode nos ajudar a compreender a branquidade, isto é, o privilégio racial (branco), e a operacionalização do racismo no meio acadêmico brasileiro.

\section{Uma hipótese de trabalho: a branquidade em espaços de decisão acadêmica}

\section{Branquidade}

5

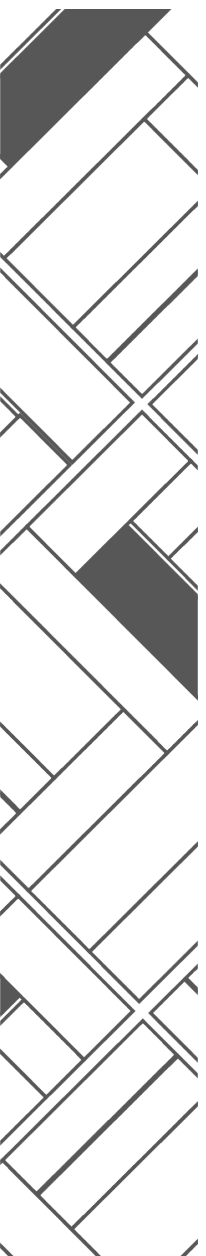

Buscaremos responder a questão acima tendo como hipótese de trabalho que tal deliberação foi tomada em razão da branquidade, isto é, do poder e privilégio raciais dos conselheiros do CEPE. Conjecturamos que eles deliberaram tal assunto em face das convicções de possuírem qualificação e capacidade intelectuais para deliberar sobre o tema por serem brancos, isto é, em razão de terem incorporado consciente ou inconscientemente ao longo de suas vidas, bem como ao longo de suas formações acadêmico-científicas ${ }^{4}$, a ideia de que a superioridade da sua cor/raça (branca) ${ }^{5}$ os permitem conhecer e decidir sobre variados temas ou assuntos, especialmente os relativos à vida dos negros, mesmo aqueles conselheiros não sabendo nada (acadêmico-cientificamente) sobre questões relacionadas às relações raciais brasileiras

4 A incorporação da ideia acima, ao longo da vida se deve, entre outros fatores, à socialização racista dos brasileiros. O incremento dessa mesma ideia na formação acadêmica é um dos resultados do "confinamento racial do mundo acadêmico brasileiro", conforme Carvalho (2005-2006).

5 Raça entendida como construção social. 
Ambiente acadêmico brasileiro: branquidade e exclusão de direitos dos estudantes negros

e/ou às políticas de promoção da igualdade racial que o país começou a implementar a partir da década de 2001 (SANTOS, 2014).

Para muitos cidadãos comuns e acadêmicos, sustentar tal hipótese é meio controverso ou até mesmo implausível, não somente porque nós brasileiros, especialmente os brancos, tendemos a negar a branquidade e/ou resistimos a estudar o tema (BENTO, 2002a), mas também porque há várias definições de branquidade (WARE, 2004), embora elas tenham um denominador comum: o destaque aos privilégios raciais das e para as pessoas consideradas brancas (BENTO, 2005; FRANKENBERG, 2004; SOVIK, 2004; WARE, 2004), aspecto que mais nos interessa destacar sobre a discussão desse assunto.

Considerando os objetivos deste artigo, focaremos as definições de branquidade (muito semelhantes) de três autoras, bem como as suplementaremos, para sustentar nossos argumentos e hipótese, como se verá mais à frente. Assim, a primeira definição que apresentaremos é da professora Liv Sovik. Conforme essa pesquisadora, branquidade é entendida como "um lugar de fala confortável, privilegiado e inominado, de onde se tem a ilusão poderia acrescentar-se - de observar sem ser observado" (SOVIK, 2004, p. 368). Definição muito parecida com uma das oito definições elaboradas pela professora Ruth Frankenberg (2004, p. 312), qual seja, "branquidade é um lugar de vantagem estrutural nas sociedades estruturadas na dominação racial". A terceira definição é da pesquisadora Maria Aparecida da Silva Bento, segundo a qual "branquitude é o reconhecimento de que a raça, como um jogo de valores, experiências vividas e identificações afetivas, define a sociedade" (BENTO, 2002a, p. 163).

Como se pode observar, a pesquisadora Bento (2002a) utiliza o termo branquitude em vez de branquidade ao longo da sua tese de doutorado, bem como em outros artigos (BENTO, 2002b, 2005), para destacar e/ou demonstrar a identidade, o poder e 0 privilégio raciais das pessoas consideradas brancas no Brasil. Em realidade, pode-se afirmar que ela utiliza o termo branquitude 
Ambiente acadêmico brasileiro: branquidade e exclusão de direitos dos estudantes negros Sales Augusto dos Santos

como sinônimo de branquidade ${ }^{6}$, pois ao citar a pesquisadora Frankenberg, que utiliza o termo branquidade e não branquitude (FRANKENBERG, 2004), Bento afirma que

ela [Frankenberg] entende branquitude como um posicionamento de vantagens estruturais, de privilégios raciais. Também ressalta que é um ponto de vista, um lugar a partir do qual as pessoas brancas olham a si mesmas, aos outros e à sociedade. Finalmente, observa que a branquitude diz respeito a um conjunto de práticas culturais que são normalmente não-marcadas e não-nomeadas (BENTO, 2002a, p. 164)7.

Evidentemente que o lugar de fala com privilégios (raciais) ou de vantagem estrutural acima citados é o lugar social dos e/ou ocupado pelos cidadãos considerados brancos em uma determinada sociedade, como, por exemplo, a brasileira. Por conseguinte, nessa sociedade há a dominação racial citada por Frankenberg (2004), consequentemente, há também subordinação racial dos não brancos, assim como desigualdades e opressões raciais contra esses $^{8}$, especialmente contra os negros, inclusive no meio acadêmico, conforme demonstram IBGE (2019), Almeida (2018), Santos (2014), Waiselfisz (2014 e 2012), Marcondes et. al. (2013), IPEA (2011), Divino (2016), Carvalho (2005-2006 e 2005), entre outras instituições e autores. Portanto, a branquidade no Brasil indica quem tem poder em sentido amplo e quem não o tem; quem tem acesso ao exercício pleno da cidadania e quem não o tem, num país formalmente democrático, multirracial, mas racista, que tenta evitar a todo custo que os negros e os indígenas sejam donos de seu destino (NASCIMENTO, 1985, 1982 e 1980; RAMOS, 1995).

Mais ainda, ao que tudo indica, o "lugar de fala confortável", especialmente no meio acadêmico, erige-se em discurso com-

\footnotetext{
6 Liv Sovick (2004) e Lourenço Cardoso (2014) também utilizam esses termos como sinônimos.

7 Bento (2002a) está se referindo ao livro White Women, Race Matters: the Social Constrution of whitness, de Frankenberg, cuja primeira publicação foi em 1993. Contudo, Frankenberg (2004), no artigo "A miragem de uma branquidade não-marcada", questiona se a branquidade ainda está invisível discursivamente, se ela de fato não é marcada, como indicado na última parte da citação feita por Bento.

8 Mas há, evidentemente, reações da população negra contra o racismo, conforme Santos (2014), ENMZ (1996), entre outros.
} 
Ambiente acadêmico brasileiro: branquidade e exclusão de direitos dos estudantes negros Sales Augusto dos Santos

petente ${ }^{9}$, estabelecendo quem pode enunciar o quê, como, para quem, quando ou sobre quem. Como exemplo dessa assertiva, podemos citar a tentativa de operacionalização da branquidade conduzida pelo cientista social Luís Aguiar Costa Pinto, branco, contra o sociólogo Alberto Guerreiro Ramos, afro-brasileiro, que juntamente com Sebastião Rodrigues Alves ${ }^{10}$ criticaram o livro 0 negro no Rio de Janeiro: relações de raça numa sociedade em mudança (1953), publicado por Aguiar Costa Pinto. A crítica foi tanto pela obra em si quanto sobre a maneira como o cientista social Costa Pinto fazia ciência, ou seja, vendo o "tema do negro"11 ou, se se quiser, tratando os negros como objeto de pesquisa ou "material de laboratório".

As críticas de Guerreiro Ramos e Rodrigues Alves ao livro de Costa Pinto geraram uma polêmica pública, visto que a resposta de Costa Pinto a elas foi desqualificadora dos seus críticos. Conforme afirmação desse autor, "duvido que haja biologista que depois de estudar, digamos, um micróbio, tenha visto esse micróbio tomar da pena e vir a público escrever sandices a respeito do estudo do qual ele participou como material de laboratório" (COSTA PINTO apud NASCIMENTO, 1982, p. 61-62).

Como se observa, o lugar de fala de Costa Pinto, com privilégios raciais (brancos), permitia desumanizar os seus críticos negros sem a possibilidade de haver sanções acadêmicas contra o agressor por parte de seus pares brancos, em razão do pacto narcísico, conforme acepção de Bento (2002a), e, é claro, do lugar social ocupado pelo intelectual branco Costa Pinto à época.

Mas antes de finalizar este item, e em razão dos objetivos deste artigo, pensamos ser necessário suplementar as definições de

\footnotetext{
9 Conforme a filósofa Marilene Chaú, "o discurso competente é o discurso instituído. É aquele no qual a linguagem sofre uma restrição que poderia ser assim resumida: não é qualquer um que pode dizer a qualquer outro qualquer coisa em qualquer lugar e em qualquer circunstância. $O$ discurso competente confunde-se, pois, com a linguagem institucionalmente permitida ou autorizada, isto é, com o discurso no qual os interlocutores já foram previamente reconhecidos como tendo o direito de falar e ouvir, no qual os lugares e as circunstâncias já foram predeterminados para que seja permitido falar e ouvir e, enfim, no qual o conteúdo e a forma já foram autorizados segundo os cânones da esfera de sua própria competência." (CHAUÍ, 1990, p. 7). 10 Este foi um dos militantes fundadores do Teatro Experimental do Negro (TEN), junto com Abdias Nascimento e outros (NASCIMENTO, 1980, p. 126).

11 Conforme Guerreiro Ramos (1995, p. 215), "negro-tema é uma coisa examinada, olhada, vista, ora como ser mumificado, ora como ser curioso, ou de qualquer modo como um risco, um traço da realidade nacional que chama a atenção". Contrapondo-se a essa concepção, Guerreiro Ramos afirma que os negros são sujeitos do conhecimento e, além disso, devem ser vistos e/ou tratados como "negro-vida". Este é "algo que não se deixa imobilizar; é despistador, proteico, multiforme, do qual, na verdade, não se pode dar versão definitiva, pois é hoje o que não era ontem e será amanhã o que não é hoje" (RAMOS, 1995, p. 215).
} 
Ambiente acadêmico brasileiro: branquidade e exclusão de direitos dos estudantes negros Sales Augusto dos Santos

branquidade de Bento (2002a), Sovik (2004) e Frankenberg (2004), inclusive para dar mais suporte à nossa hipótese, visto que para nós a branquidade significa muito mais que racializar o "outro"12, até porque, como se verá neste artigo, os brancos brasileiros também se autorracializam (positivamente) em determinados momentos e/ou contextos. Assim, o privilégio racial também significa ou implica, entre outros aspectos:

a) O controle pela "raça dominante"13 (ou por indivíduos dessa raça) de quem pode ser considerado cidadão, exercer a cidadania, circular tranquila ou confortavelmente em espaços públicos, e, principalmente, exercer poder. ${ }^{14}$ Isto é, em face do racismo sistêmico brasileiro (ALMEIDA, 2018) alguns membros do grupo racial dominante têm e/ou exercem o poder de, por um lado, incluir ou excluir os não brancos, especialmente negros e indígenas, entre os sujeitos que têm o direito de usufruir os bônus sociais produzidos na sociedade brasileira e, principalmente, por outro lado, incluir os brancos como sujeitos de direito desses bônus, mesmo quando legalmente isso não é possível.

Como exemplo desse último caso, citamos um acordo extrajudicial feito entre a reitora temporária da Universidade Federal da Grande Dourados (UFGD), Mirlene Ferreira Macedo Damazio, e o Ministério Público Federal (MPF). O acordo visava a beneficiar estudantes brancos fraudadores das subcotas étnico-raciais, conforme relatou André Bento (2019 e 2020). Segundo esse, alguns alunos brancos do curso de Medicina da UFGD foram denunciados por terem fraudado as subcotas étnico-raciais destinadas a estudantes pretos, pardos e indígenas. Após as denúncias, em 2018, a UFGD, sob a direção da então reitora Liane Calarge, criou uma comissão para verificar as fraudes denunciadas. Essa comissão fez a heteroidentificação dos alunos denunciados e constatou que, de fato, havia diversos estudantes brancos fraudadores das subcotas

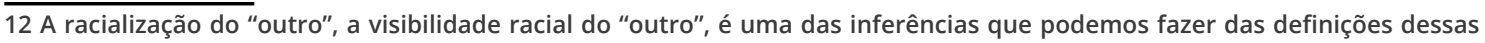
autoras.

13 Conforme expressão de Florestan Fernandes (1972), para designar os brancos no Brasil.

14 Evidentemente que esse controle não é total, absoluto ou pleno. Assim, poucos negros, por vários motivos que não temos como explorar aqui - ante ao espaço que temos para produzir este artigo -, conseguem atravessar as rígidas barreiras impostas a eles para não usufruírem os bônus sociais produzidos na sociedade brasileira. Mas isso não implica que esses raros negros viverão sem sofrer discriminações e/ou insultos raciais nessa sociedade.
} 
Ambiente acadêmico brasileiro: branquidade e exclusão de direitos dos estudantes negros Sales Augusto dos Santos

étnico-raciais. Os relatórios da referida comissão sobre os casos foram encaminhados às instâncias superiores da universidade para as devidas providências. Assim, em 11 de fevereiro de 2019, a UFGD cancelou a matrícula de alguns estudantes brancos do curso de Medicina que haviam ingressado nas subcotas étnico-raciais destinadas aos estudantes pretos, pardos e indígenas.

Os estudantes desligados da UFGD por fraude recorreram administrativamente ao Conselho Universitário (Couni) da instituição visando a impedir o cancelamento de suas matrículas, mas tiveram seus pedidos negados. Cinco desses estudantes também recorreram à Justiça Federal, mas o Tribunal Regional Federal da $3^{a}$ Região (TRF3) também negou os seus pedidos, ratificando, em abril de 2019, a decisão da UFGD que cancelou as matrículas dos estudantes fraudadores das subcotas étnico-raciais, expulsando-os da universidade (BENTO, 2019).

Todavia, em setembro de 2019, sob a gestão da reitora temporária Mirlene Damazio, a UFGD supreendentemente desobedeceu à determinação da Justiça Federal e entabulou um acordo extrajudicial com o MPF para readmitir os estudantes na universidade. Segundo Bento (2019), essa reitora "readmitiu ex-alunos do curso de Medicina que haviam tido as matrículas canceladas por suposta fraude no sistema de cotas (...). O retorno dos acadêmicos foi possível graças a termo de composição extrajudicial firmado com a mediação do MPF (...)". ${ }^{15}$

No entanto, uma organização do movimento negro, o Coletivo de Mulheres Negras de Mato Grosso do Sul "Raimunda Luzia de Brito", impetrou uma ação na Justiça Federal contra esse acordo, afirmando que ele era ilegal. Segundo Bento (2020), a Justiça Federal acatou o pedido formulado pelo coletivo e determinou o cancelamento do acordo supracitado, ordenando à reitora Mirlene Damazio desfazê-lo. Ou seja, a Justiça Federal negou o reingresso à universidade dos estudantes brancos fraudadores das subcotas

15 Disponível em: https://www.douradosnews.com.br/dourados/reitora-reintegra-alunos-de-medicina-afastados-por-suposta-fraude-em/1111173/. Acesso em: 21 mai. 2020. 
Ambiente acadêmico brasileiro: branquidade e exclusão de direitos dos estudantes negros Sales Augusto dos Santos

étnico-raciais, determinação que a reitora supracitada insistia em descumprir.

Eis aí uma tentativa de mobilização da branquidade por meio da inclusão dos brancos como sujeitos de direito de uma política pública, mesmo quando legalmente isso não é permitido. Tal ação racional com relação a fins (WEBER, 1964) da então reitora temporária da UFGD, Mirlene Damazio, confirma a operacionalização que Maria Aparecida da Silva Bento (2002a) denominou de pacto narcísico: "um pacto silencioso de apoio e fortalecimento aos iguais (brancos). Um pacto que visa preservar, conservar a manutenção de privilégios (raciais) e de interesses" (BENTO, 2002a, p. 105-106).

b) O privilégio racial também implica segurança corporal-física, mental-intelectual e psíquica aos cidadãos considerados brancos, para viverem sem receio de sofrer discriminações e/ou violências físicas e/ou simbólicas de todas as ordens em razão de representações negativas relativas à sua cor de pele, visto que esses não são estigmatizados racialmente no Brasil. Dito de outra maneira, branquidade implica a garantia de que, por ser identificado ou considerado como branco, o cidadão não vai ser espancado ou assassinado pela polícia por causa de sua cor/raça, bem como não vai ser condenado injustamente pelo Poder Judiciário ou penalizado mais do que deveria ser em caso de cometimento de algum crime ${ }^{16}$; não vai deixar de receber cuidados adequados nos hospitais durante consultas ou tratamentos médicos ${ }^{17}$; vai poder entrar e sair tranquilamente de shopping centers $^{18}$ ou supermercados sem ser vigiado constantemente ou até mesmo atacado por seguranças; vai poder cursar uma excelente universidade sem que os professores desconfiem da sua capacidade intelectual e/ou de que

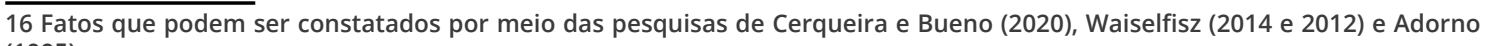
(1995).

17 Por exemplo, conforme Sabrina Petry (2002), “Hospitais e maternidades, públicos e particulares, da cidade do Rio de Janeiro tratam melhor as gestantes brancas do que as negras. (...). O estudo [com 10 mil mulheres, realizado pela Fiocruz] apontou que até nesse aspecto [anestesia no parto normal] as mulheres negras sofreram preconceito: $11,1 \%$ delas não receberam anestésico, pouco mais do que o dobro do percentual das brancas que não foram anestesiadas (5,1\%)". Quinze anos depois da pesquisa supracitada, Leal et al. (2017) demonstraram que essas violências raciais contra as mulheres negras continuam acontecendo no Brasil.

18 Por exemplo, a pesquisadora Lia Schucman relata que um dos seus entrevistados, um "rapaz loiro de olhos azuis morador de rua", ao ser perguntado por ela o que é ser branco, responde: "Ser branco? ah, ser branco é poder entrar no shopping para cagar" (SCHUCMAN, 2014, p. 139).
} 
Ambiente acadêmico brasileiro: branquidade e exclusão de direitos dos estudantes negros

estudante não mereça estar no mundo acadêmico, entre outras violências raciais.

Quanto à última violência racial enunciada, vale a pena citar a desconfiança, o desprezo, o desrespeito, o preconceito etc., manifestados pelo professor Paulo Palma, da Faculdade de Ciências Médicas (FCM) da Universidade Estadual de Campinas (Unicamp). Ao se posicionar contrário à aprovação do sistema de cotas étnico-raciais para estudantes negros na universidade, em 01/06/2017, o professor afirmou que "a universidade é para a elite cultural do Brasil, não para vagabundo". Ou seja, para o referido professor todos os estudantes pretos, pardos e indígenas, que seriam os beneficiários das cotas supracitadas, são vagabundos. Não bastasse isso, o docente arremata:

Em vez de corrigir o problema, dão cotas para quem não tem condição de acompanhar. Não digo cursos como dança. Digo cursos técnicos que exigem um pouco mais de QI [...]. Quando permite cota, ela (a universidade) está trocando cérebro por nádegas ou por cor de pele e outros valores. ${ }^{19}$

As afirmações do professor Paulo Palma, que refletem os pensamentos, sentimentos, valores, crenças e ideais de boa parte das elites dirigentes brasileiras (esmagadoramente brancas), expressam o brancocentrismo em nosso país ou, se se quiser, a colonialidade (interna) do poder, do ser e do saber (QUIJANO, 2005). Essas colonialidades, como se sabe, têm a ver com a tentativa ou a busca incessante de subalternização interna dos negros e indígenas em nosso país. Frise-se que o que denominamos de brancocentrismo não é muito diferente do eurocentrismo, especialmente no que diz respeito a considerar a cultura europeia, assim como a maioria dos seus agentes humanos (isto é, os homens e mulheres brancos/as), como precursores da história e do desenvolvimento da humanidade, transformando-se assim em referências ou modelos

19 Disponível em: http://correio.rac.com.br/_conteudo/2017/06/campinas_e_rmc/481708-professor-da-unicamp-anticotas-gera-polemica.html. Acesso em: 28 ago. 2017 (grifos nossos). 
Ambiente acadêmico brasileiro: branquidade e exclusão de direitos dos estudantes negros Sales Augusto dos Santos

(superiores) universais para as demais culturas e/ou países e povos.

c) O privilégio racial no Brasil também significa ou implica, por um lado, que o indivíduo ou grupo racializador (subjugador) não viverá sob o mesmo stress racial que o grupo racializado (subjugado) vive, o que garante àquele uma vantagem competitiva incalculável nas disputas por bônus sociais com os "outros" racializados, especialmente em uma sociedade que além de racista é capitalista, isto é, também é marcada pela colonialidade do poder, do saber e do ser (QUIJANO, 2005; MIGNOLO, 2008 e 2003; BERNARDINO-COSTA, MALDONADO-TORRES e GROSFOGUEL, 2018). Por outro lado, esse indivíduo branco sempre terá o suporte da "mão invisível" da "raça dominante", isto é, ele terá a ajuda do que denominamos de rede de proteção racial (branca), estruturada e estruturante, que incrementará a sua trajetória pessoal, econômico-profissional, educacional-intelectual, a sua segurança física, o seu equilíbrio psíquico-emocional, entre outros, o que o torna seguro e confiante frente às possíveis disputas por bônus sociais, entre outras, com pessoas consideradas negras ou indígenas, como o exemplo que será visto mais à frente no processo de admissão de um professor de História, em 1996, num dos mais importantes colégios da cidade de São Paulo.

Deve-se destacar que mesmo que alguns indivíduos do grupo racial dominante sejam contrários e/ou lutem abertamente contra o racismo sistêmico brasileiro que alimenta essa rede (e vice-versa), ela não vai deixar de existir, bem como não deixará de operar em favor de todos os cidadãos considerados brancos, quer sejam eles críticos ou acríticos da branquidade, quer sejam eles racistas, não racistas ou mesmo antirracistas.

d) O privilégio racial implica a operacionalização do poder racial (branco), o seu exercício e autousufruto sem necessariamente a enunciação explícita desse poder ${ }^{20}$, mas consciente dele, ante ao que Bento (2002a) denominou de pacto narcísico, que é uma

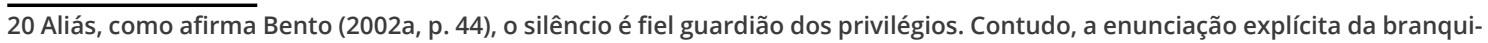
dade ocorre em determinadas circunstâncias, como se verá mais à frente. 
Ambiente acadêmico brasileiro: branquidade e exclusão de direitos dos estudantes negros Sales Augusto dos Santos

das características fundamentais da branquidade brasileira, como visto anteriormente.

\section{Circunstâncias excepcionais e objeção de consciência aos princípios metodológicos}

Apesar de adotarmos uma definição que conecta ou equipara a branquidade ao privilégio racial, focando-a como resposta ao problema supracitado, por princípio metodológico não concebemos primazia da categoria raça/cor sobre outras categorias ou, caso se queira, sobre outras forças sociais opressivas. Dito de outra forma, ao analisarmos um problema ou um fato social não podemos nos esquecer da influência ou do poder de interferência de outras categorias sobre o problema ou fato social em análise. Ou seja, segundo pensamos, a análise de um problema social deve levar em consideração a metodologia interseccional (CRENSHAW, 2002), especialmente em sociedades multirraciais e capitalistas, como a brasileira, que também é racista, classista, sexista, homofóbica etc. (MARCONDES et. al., 2013; IPEA, 2011; IBGE, 2019; CERQUEIRA e BUENO, 2020). Portanto, analisá-la ou analisar seus problemas sociais implica levar em consideração os vários eixos de subordinação que nela existem. Eixos que se interseccionam, que interagem uns com os outros, pelos outros e contra os outros, como a raça/cor, a classe, o sexo/gênero, a orientação sexual, a origem regional, a nacionalidade, a compleição física, a religião, entre tantos outros que criam, recriam, impulsionam, produzem e/ou reproduzem discriminações, exclusões, opressões, desigualdades e mortes. Isto é, esses eixos de subordinação possibilitam, catalisam e proporcionam discriminações, opressões e desigualdades não apenas em razão da raça ou da identidade racial dos indivíduos.

Todavia, adotar a interseccionalidade como princípio metodológico, como temos feito ao longo da nossa trajetória acadêmica, não implica necessariamente a adoção de um dogmatismo 
Ambiente acadêmico brasileiro: branquidade e exclusão de direitos dos estudantes negros

metodológico, isto é, da não flexibilização desse princípio para "leitura" da sociedade brasileira e/ou de determinados problemas dessa sociedade ante a determinadas circunstâncias, situações, ambientes, contextos, conjunturas e atores sociais envolvidos. Em circunstâncias específicas, como demonstraremos logo a seguir, por um lado, a raça/cor pode ser a única e/ou a principal categoria social de opressão acionada para garantir e/ou exigir privilégios, prestígio, exercício do poder, mando e comando por determinado grupo racial, e, por outro lado, pode ser acionada para desqualificar, humilhar, desmerecer, desconhecer, discriminar, excluir e/ou oprimir e até eliminar outro/s grupo/s racial/is, como comprovam as pesquisas de Cerqueira e Bueno (2020) e de Waiselfisz (2014 e 2012).

Como indicado acima, há casos explícitos ou gritantes em que a raça/cor, logo a identidade racial, foi a única categoria social de opressão usada para discriminar e/ou excluir os negros dos bônus sociais produzidos na sociedade brasileira. Como exemplo citamos o processo de admissão de um professor de História, em 1996, num dos mais tradicionais e importantes colégios da cidade de São Paulo, como relata um dos professores, branco, que participou do processo seletivo.

À época do processo seletivo, o professor branco supracitado ainda não havia concluído a graduação do curso de História, embora estivesse realizando o último ano do curso na Universidade de São Paulo (USP). Ao participar desse processo seletivo com dezenas de outros candidatos, visando ao ingresso na escola supracitada, mas com pouca experiência como professor, depois de passar em duas fases, respectivamente prova escrita e testes psicológicos, ele (branco) e outro candidato (negro) foram os únicos professores que passaram para a terceira e última fase do processo: uma entrevista com a direção da escola. No dia da entrevista, prevista para as $16 \mathrm{~h}$, o professor branco chegou ao local antes do horário marcado e acabou vendo o seu concorrente, que foi o primeiro a ser entrevistado. Ao vê-lo, o então candidato branco teve a certeza, antes mesmo da sua entrevista, de que seria o professor que 
ocuparia a vaga em disputa, e não o candidato negro. Ele sabia que o pacto narcísico (BENTO, 2002a) seria acionado e que o exercício do poder branco ou a branquidade seria operacionalizada em seu favor. Segundo o professor,

Eram 15:50h quando o outro candidato acabou a entrevista e abriu a porta da direção. Eu o conhecia de vista. Era também da USP. Diferentemente de mim, ele já era formado em História. Mais que isso, tinha mestrado e doutorado. (...). Eu já havia assistido algumas palestras desse meu "concorrente" na própria universidade. Ele era inteligente, falava muito bem e era muito bem apresentável. Quando ele me viu, abriu um sorriso e perguntou: “Ei! Você não é um bicho da História?" estendi minhas mãos, o cumprimentei e cordialmente respondi, "Sou... Você é aluno do Elias, não é...?" Ele confirmou, nos despedimos e ele partiu. Nesse momento me senti absolutamente aliviado... Mais que isso, me senti feliz... Pois tinha agora a certeza de que havia conseguido aquele emprego... Por maiores que fossem as qualidades profissionais de meu "oponente" sobre as minhas qualidades, por mais esmagadora que fosse a superioridade de seu currículo em relação ao meu, eu sabia que eu tinha conseguido finalmente aquele emprego. Tudo por uma simples razão: meu "concorrente" tinha uma pequena diferença em relação a mim, ele era negro. $E$ eu sabia que aquela escola - frequentada pela mais alta elite paulistana, reacionária e branca - nunca empregaria um negro como professor, principalmente porque eu, o outro candidato, era branco e de olhos verdes. Saí da entrevista com os diários de classe, uma jornada de 32 horas aulas semanais e um excelente salário. Ao longo da "entrevista" todas as minhas desvantagens se tornaram vantagens. Eu era jovem e inexperiente, assim - segundo a diretora e a coordenadora - poderia me tornar um professor do jeito que a escola queria. Na verdade, fui contratado porque eu era branco e de olhos verdes e o outro candidato era negro e de olhos negros. Não nego os meus méritos pessoais de 
Ambiente acadêmico brasileiro: branquidade e exclusão de direitos dos estudantes negros

ter chegado até aquele momento. Estudava (e estudo) muito, tive esperteza e fui eloquente. Mas aquele candidato era muito superior a mim em todos os aspectos profissionais que poderíamos aplicar. Seu único "problema" era ser negro. ${ }^{21}(-$ Grifos nossos).

No referido processo seletivo, o candidato negro era incomparavelmente mais qualificado do ponto de vista acadêmico-científico que o candidato branco, como este reconheceu. O historiador negro já possuía o título de doutor em História obtido na mais prestigiada universidade brasileira à época, a USP. O professor branco sequer havia concluído a graduação em História. Mas esse último foi o contratado pelo colégio porque ele era branco e o seu concorrente negro, como explicitado na citação. Frise-se que quem relatou esse fato, marcando e demarcando a identidade racial dos envolvidos não foi o professor negro, mas o professor autodeclarado e reconhecido socialmente como branco.

A demarcação e valorização da cor/raça branca pelos brancos e para os brancos não foi invisível, como insistem alguns autores/ as que pesquisam a branquidade, como, por exemplo, Piza (2000), nem "silenciosa". Ao contrário, foi visível e gritante. Ou seja, o professor branco foi privilegiado racialmente. Dito de outra maneira, a branquidade e o poder racial branco foram exercidos, foram colocados em ação, como acontece todos os dias na vida dos brasileiros, isto é, quando eles vão aos shoppings centers, aos supermercados, aos bancos, aos aeroportos, às escolas, às universidades, a festas, a clubes recreativos, em busca de emprego, de assistência médica, de assistência jurídica, quando são abordados pela polícia ou simplesmente quando andam na rua, entre outras possibilidades.

Assim, o professor branco, sabedor da e demonstrando a visibilidade da branquidade, 22 indicando que sua identidade racial branca é marcada e demarcada não somente pelos não brancos,

21 Disponível em: https://www.diariodocentrodomundo.com.br/ele-foi-aprovado-numa-selecao-porque-o-outro-candidato-era-negro-e-relembra-essa-historia. Acesso em: 06 de jun. de 2015.

22 Que foi ratificada pela direção do colégio supracitado. 
Ambiente acadêmico brasileiro: branquidade e exclusão de direitos dos estudantes negros Sales Augusto dos Santos

mas também pelos próprios brancos (FRANKENBERG, 2004), como, por exemplo, na passagem "fui contratado porque eu era branco e de olhos verdes e o outro candidato era negro e de olhos negros", demonstrando ser plenamente consciente da sua identidade racial branca e, consequentemente, dos privilégios e dos poderes proporcionados pela branquidade numa sociedade racista, mais ainda, demonstrando plena consciência de que a branquidade seria invocada e usada pelos membros (brancos) da direção do colégio em seu favor, teve a certeza que o seu capital racial seria apreciado e valorizado ${ }^{23}$ pela escola, não importando quão qualificado fosse o seu concorrente (negro). Não bastasse isso, essa consciência deuIhe segurança psíquica, confiança para ir à entrevista com mais tranquilidade (ou com mais "esperteza" e "eloquência"), isto é, com "a certeza de que havia conseguido aquele emprego", pois sabia que o pacto narcísico (BENTO, 2002a) o privilegiaria. O emprego, segundo o próprio candidato branco, seria (e foi) seu, porque ele se identificava e era identificado socialmente como branco, logo, teria (e teve) privilégios raciais em relação aos negros na sociedade brasileira.

Neste caso não restam dúvidas de que houve a preponderância do uso da categoria raça/cor (logo, do usufruto exclusivo do privilégio racial, da branquidade) para, de um lado, discriminar, excluir e oprimir os cidadãos negros e, de outro lado, beneficiar e empoderar ainda mais os brancos numa sociedade racista contra os negros. Assim, em que pese, no geral, o nosso princípio metodológico de não atribuir centralidade à raça, isto é, de não tê-la como único fator explicativo de discriminações, exclusões e opressões contra os negros ou, caso se queira, de não tê-la como único fator explicativo para a operacionalização de injustiças (em detrimento do peso explicativo das demais forças sociais de opressão interseccionadas com a raça/cor), ao que tudo indica, a raça/cor foi a única diferença explícita entre os professores, o único fator social de opressão usado contra o candidato negro.

23 Em realidade o seu capital racial (branco) foi sobrevalorizado, considerando que não havia como comparar as suas qualificações profissionais com as qualificações do professor negro. Este tinha um currículo "esmagadoramente superior" ao daquele, conforme o próprio professor branco relatou. 
Ambiente acadêmico brasileiro: branquidade e exclusão de direitos dos estudantes negros Sales Augusto dos Santos

em Estatística e Melhoramento Vegetal; um/a tem graduação em Medicina Veterinária e doutorado em Ciências Morfológicas; um/a tem graduação e doutorado em Física; um/a tem graduação em Informática e doutorado em Engenharia de Sistemas e Computação; um/a tem graduação em Economia Doméstica e doutorado em Engenharia de Produção; um/a tem graduação em Farmácia Industrial e doutorado em Química Orgânica; um/a tem graduação em Engenharia Agronômica e doutorado em Genética e Melhoramento; um/a tem graduação em Nutrição e doutorado em Ciência e Tecnologia de Alimentos; dois/duas têm graduação em Engenharia Florestal, sendo que um/a desses/as tem mestrado em Ciência Florestal; e, por fim, um/a tinha graduação em Análise e Desenvolvimento de Sistemas. ${ }^{25}$

Constata-se assim que a maioria absoluta desses docentes tinha formação acadêmica bem distinta, embora eles tivessem alguns pontos em comum, como, por exemplo: a) nenhum deles tinha, na época, a questão racial brasileira como tema central de pesquisa. Eles sequer estudavam políticas de promoção da igualdade racial e/ou políticas de ação afirmativa para a população negra no ensino superior. Consequentemente não tinham conhecimento acurado sobre o tema, como em geral os acadêmicos têm ou deveriam ter sobre o que enunciam e/ou deliberam academicamente; b) todos os conselheiros do CEPE que participaram daquela reunião que decidiu o destino de centenas de jovens negros eram (são) brancos. ${ }^{26}$

\footnotetext{
25 Essas informações foram obtidas do Currículo Lattes dos membros dos CEPE que participaram da reunião desse conselho realizada no dia 08 de março de 2017.

26 Como relatado em Santos e Freitas (2019b), nós havíamos criado uma comissão, que denominamos de Comissão de Aferição "Paralela" de Autodeclaração Étnico-Racial, para fazer uma segunda heteroidentificação dos estudantes que já haviam sido heteroidentificados pela CVAER da UFV. Assim, solicitamos aos membros dessa comissão paralela que também fizessem a heteroidentificação, por meio de fotografias, dos conselheiros do CEPE que participaram da reunião do dia 08 de março de 2017. Todos os conselheiros que participaram dessa reunião foram heteroidentificados como brancos pelos membros da Comissão de Aferição "Paralela" de Autodeclaração Étnico-Racial. Deve-se destacar que ela era "composta por cinco cidadãos viçosenses: a) uma estudante homossexual de um dos cursos de graduação do Centro de Ciências Humanas, Letras e Artes da UFV, autodeclarada e reconhecida socialmente como branca; b) uma cidadã heterossexual, autodeclarada e reconhecida socialmente como preta, residente em Viçosa, mestre em educação pela UFV e professora de educação básica; c) um estudante de um dos cursos de graduação do Centro de Ciências Humanas, Letras e Artes da UFV, heterossexual, autodeclarado e reconhecido socialmente como pardo; d) um cidadão homossexual, residente em Viçosa, autodeclarado e reconhecido socialmente como branco; e e) uma servidora técnico-administrativo da UFV, heterossexual, autodeclarada e reconhecida socialmente como preta. Assim, quanto ao sexo, havia três mulheres e dois homens; quanto à orientação sexual havia três heterossexuais e dois homossexuais: quanto à raça/cor, havia duas pessoas brancas, duas pretas e uma parda" (SANTOS E FREITAS, 2019b, p. 47-48). A deliberação foi por maioria dos votos dos membros da comissão. Portanto, como se observa, foram os membros da Comissão de Aferição "Paralela" de Autodeclaração Étnico-Racial que heteroidentificaram os conselheiros do CEPE supracitados, e não nós pessoalmente.
} 
Ambiente acadêmico brasileiro: branquidade e exclusão de direitos dos estudantes negros

Este dado ou fato, a identificação racial dos conselheiros, é relevante, especialmente quando se leva em consideração a análise de Carvalho (2005-2006) sobre a formação monocromática dos docentes brasileiros. Segundo Carvalho, há "uma situação de confinamento racial vivida por nós, docentes das universidades públicas brasileiras". Este confinamento é caracterizado, principalmente, por haver uma trajetória acadêmica praticamente sem experiência de diversidade racial na formação dos docentes universitários brancos brasileiros. Carvalho (2005-2006, p. 92) chega a essa conclusão após pesquisar a composição racial dos docentes de algumas das principais universidades Brasil, como, por exemplo, USP, Unicamp, UnB, Universidade Federal do Rio Grande do Sul (UFRGS), Universidade Federal de Minas Gerais (UFMG), Universidade Federal do Rio de Janeiro (UFRJ), entre outras, totalizando 18.400 acadêmicos pesquisados. Entre outros resultados, Carvalho (2005-2006) constatou que 99,60\% dos docentes eram brancos e $0,40 \%$ eram negros, não se constatando docentes indígenas entre os pesquisados.

Refletindo sobre esses dados, Carvalho (2005-2006) afirma que se ele escolhesse aleatoriamente um professor do grupo pesquisado, muito provavelmente esse teria sido um branco, com poucos colegas negros no ensino médio, raríssimos na graduação e mais raro ainda nos cursos de mestrado e de doutorado, além de muito provavelmente esse docente ter tido somente professores brancos ao longo da sua trajetória acadêmica. Ou seja, esse docente praticamente viveu uma trajetória escolar-acadêmica sem diversidade racial, ou melhor, completamente monocromática: branca. Mas ainda, quando esse professor ingressa em uma universidade pública brasileira, esse processo é reproduzido, ou seja, praticamente todos os seus pares serão brancos, assim como a maioria dos seus estudantes de graduação, bem como praticamente todos estudantes de mestrado e de doutorado. Ante a isso, Carvalho conclui: 
Ambiente acadêmico brasileiro: branquidade e exclusão de direitos dos estudantes negros

Como consequência desse confinamento, em algumas faculdades mais fechadas e elitizadas, é perfeitamente possível que um docente e pesquisador desenvolva por décadas o seu trabalho acadêmico sem conviver jamais com um único estudante negro ou com um único docente negro; quando muito, conviverá com alguns servidores negros, com os quais estabelece relações de pouca ou nenhuma identificação (CARVALHO, 2005-2006, p. 92).

A citação acima mostra, explicitamente, que o mundo acadêmico brasileiro é predominantemente branco, especialmente na pós-graduação, locus onde se produzem e/ou reproduzem intelectuais para o quadro de professores e pesquisadores das instituições universitárias e de pesquisas brasileiras. Consequentemente, mostra também a ausência de convivência de diversidade racial entre discentes e docentes ao longo da sua formação acadêmica. Ou seja, há um (auto)isolamento dos brancos no mundo acadêmico brasileiro, em razão de este ser preponderantemente branco, como demonstrou Carvalho (2005-2006).

Contudo, no subtexto da citação é possível ler, similarmente, a formação, a reprodução, o fortalecimento, a consolidação e o aprofundamento dos laços sociais (e raciais) dos intelectuais brancos no espaço acadêmico, especialmente na pós-graduação. Consequentemente, emerge daí a formação de um capital social (BOURDIEU, 1998), racializado e racializante, que intensifica o companheirismo ou a cumplicidade (racial) entre pares acadêmicos (brancos), por estarem em um espaço de brancos (CARVALHO, 2005-2006 e 2005; DIVINO, 2016). Consequentemente, esse capital, em face das características do seu afloramento, também possibilita incrementar o capital cultural (BOURDIEU, 1998) dos discentes e docentes, especialmente uma de suas formas: no estado institucionalizado. Ou seja, é possível ver no subtexto da citação de Carvalho (2005-2006) a existência (a reprodução e a solidificação) 
Ambiente acadêmico brasileiro: branquidade e exclusão de direitos dos estudantes negros Sales Augusto dos Santos

de uma rede de proteção racial branca ${ }^{27}$ usufruída por grande parte dos acadêmicos brancos, reproduzida e solidificada pelos e para brancos, fato que reforça mais ainda os vínculos e pactos da branquidade. Portanto, o confinamento racial acadêmico é também um locus privilegiado para a otimização do que Bento (2002a) designou de pacto narcísico, um pacto entre iguais (brancos), que não é enunciado explicitamente, embora seja operacionalizado constantemente, como, por exemplo, na contratação do professor de História, citada anteriormente. Conforme Bento (2002a, p. 109), "a invisibilidade e o silêncio parecem ser a condição sine qua non para a manutenção do pacto narcísico. Todos sabem qual é o espaço do 'nosso' grupo (branco). Esse espaço não pode ser invadido".

Pode-se ver nas entrelinhas da mesma citação a ausência e/ ou a exclusão de acadêmicos negros naquele e daquele espaço ou, caso se queira, daquele grupo. Logo, se percebe o código. Isto é, não é difícil inferir, para quem nele vive, assim como para quem nele não se vê representado simbólica e fisicamente, que o meio acadêmico brasileiro de fato não é um locus para os negros (CARVALHO, 2005-2006 e 2005; DIVINO, 2016), porque nele praticamente não há negros, especialmente na pós-graduação.

Assim, nos programas de pós-graduação das universidades públicas brasileiras, o confinamento racial reimprime com tintas mais fortes a socialização racista que todos brasileiros, independentemente de sua cor/raça, tiveram e têm ao longo de suas vidas. Logo, ele aviva, potencializa, incrementa e solidifica os laços da branquidade dos docentes e discentes (brancos). Por conseguinte, é plausível inferir que os conselheiros do CEPE, todos brancos,

\footnotetext{
27 Os laços raciais estabelecidos entre os estudantes brancos na universidade, assim como a rede de proteção racial branca acadêmica supracitada, não ficam restritos ao espaço universitário e não protegem ou apoiam somente quem é acadêmico (branco). Por exemplo, quando o ex-âncora do Jornal da Globo, exibido pela Rede Globo de Televisão, o jornalista William Waack, foi demitido dessa emissora em novembro de 2017, por enunciar comentários de cunho racista contra a população negra estadunidense, conforme afirmado pela própria emissora de televisão (Disponível em: https://www.youtube.com/watch?v=nP6BcWerlpU. Acesso em: 14 abr. 2020), o jornalista Luís Nassif, do portal GGN - O Jornal de todos os Brasis, saiu em defesa do caráter de William Waack, lembrando de ações e/ou comportamentos positivos deste último quando eles estudavam jornalismo na Escola de Comunicações e Artes da Universidade de São Paulo (ECA/USP) (Disponível em: https://jornalggn.com. br/direitos/william-waack-no-corredor-polones-da-midia-por-luis-nassif/. Acesso em: 14 abr. 2020). Devemos lembrar que Luís Nassif, segundo a mídia alternativa, tem posição político-ideológica de social-democrata ou até mesmo de esquerda, ao contrário de William Waack, tachado como liberal e/ou defensor de políticas da direita. Essas diferenças político-ideológicas entre os dois jornalistas e a defesa desse por aquele nos remete a uma afirmação da doutora Sueli Carneiro (2000, p. 29), filósofa, ativista e intelectual orgânica dos movimentos negro e feminista, que, em entrevista à revista Caros Amigos, enunciou: "Sabe, entre a esquerda e a direita, sei que continuo preta". Ou seja, ao que tudo indica, o que denominamos de rede de proteção racial branca e/ou os laços profundos da branquitude rompem até barreiras ideológico-políticas para a defesa dos brancos no Brasil.
} 
Ambiente acadêmico brasileiro: branquidade e exclusão de direitos dos estudantes negros Sales Augusto dos Santos

majoritariamente pós-graduados, também foram moldados mais intensamente pelo e para o privilégio racial em face do confinamento racial no mundo acadêmico brasileiro (CARVALHO, 20052006) e do pacto narcísico (BENTO, 2002a). Esse confinamento não somente possibilitou a operacionalização da branquidade daqueles conselheiros na reunião do dia 08 de março de 2017, como a exigiu por ela ser um fato social (DURKHEIM, 1985). ${ }^{28}$

À vista disso, também é plausível sustentar que os conselheiros do CEPE decidiram o ingresso e, simultaneamente, a exclusão de estudantes negros das subcotas étnico-raciais da UFV (SANTOS e FREITAS, 2019b) pautados pela branquidade. A força cultural da branquidade, tendo como um dos seus traços fundamentais o pacto narcísico (BENTO, 2002a), os impediu inclusive de consultar os raros acadêmico-intelectuais afro-brasileiros da universidade ${ }^{29}$ para saber o que eles pensavam a respeito das políticas de ação afirmativa para estudantes negros e como operacionalizá-las. Ou seja, o destino acadêmico de dezenas de estudantes negros foi conduzido pelo privilégio racial branco e não pelo conhecimento acadêmico-científico sobre as políticas de promoção da igualdade racial.

\section{O desprezo aos intelectuais negros e à sua produção de conhecimento}

Mesmo desconhecendo profundamente as políticas de ação afirmativa para estudantes negros, como comprovam os seus Currículos Lattes, e tendo que tomar decisões sobre elas, os conselheiros do CEPE da UFV sequer convidaram os intelectuais dos campos de pesquisa e ensino supracitados para assessorá-los ou, caso se queira, iniciar um aprendizado sobre o assunto a ser de28 Relembrando, conforme Emile Durkheim (1985, p. 3), os fatos sociais “consistem em maneiras de agir, de pensar e de sentir
exteriores ao indivíduo, dotadas de um poder de coerção em virtude do qual se Ihes impõe".
29 Segundo o cientista social Divino ( 2016, p. 48 e 49$)$, em 2016 , os professores afro-brasileiros da UFV eram $8,17 \%$ (6,43\% par-
dos e $1,74 \%$ pretos) do total de docentes da instituição, enquanto os brancos eram $86,38 \%$ e os professores não identificados racialmente eram $5,45 \%$. 
Ambiente acadêmico brasileiro: branquidade e exclusão de direitos dos estudantes negros Sales Augusto dos Santos

liberado ou, ainda, tirar dúvidas, discutir prováveis problemas e suas consequências e, dessa forma, ter o mínimo de conhecimento para deliberar sobre o assunto.

Deve-se destacar que a não consulta de pares acadêmicos especialistas sobre o assunto não se deu pela ausência desses no Brasil, no Estado em que está localizada a UFV, menos ainda pela não existência desses na própria universidade. Externo à UFV havia pesquisadores renomados sobre relações raciais brasileiras e políticas de ação afirmativa, que poderiam ter sido consultados pelos membros do CEPE e os assessorado na referida tomada de decisão ${ }^{30}$, como, por exemplo, a pesquisadora Nilma Lino Gomes, da Universidade Federal de Minas Gerais (UFMG).

Conforme Santos (2014), esta renomada professora incorporou dos movimentos sociais negros a ética da convicção antirracismo, em face da influência desses em sua trajetória de vida, associando tal ética ao seu conhecimento acadêmico-científico logrado nas universidades por onde passou, especialmente nos cursos de pós-graduação. Consequentemente, a professora Nilma Gomes tornou-se uma negra intelectual, conforme a acepção proposta por Santos (2014), na medida em que os negros intelectuais têm um ethos acadêmico ativo que orienta os seus estudos, pesquisas e ações contra o racismo, logo, contra a colonialidade do poder, do saber e do ser (QUIJANO, 2005).

Como se pode observar, a professora Nilma Gomes, como os demais negros intelectuais, operacionalizou parte da perspectiva decolonial proposta por Quijano (2005) e Grosfoguel (2016), entre outros. Ou seja, os negros intelectuais com suas epistemes focadas em desconstruir o racismo (que é um dos principais pilares da colonialidade do poder), com suas buscas por igualdade e justiça para todos os cidadãos independentemente de sua cor/raça, lutam contra o colonialismo interno brasileiro, colocando em xeque a branquidade e o pensamento brancocêntrico, que só aceitam

$30 \mathrm{Em}$ realidade, em nível nacional, há centenas de pesquisadores/as renomados/as que estudam e pesquisam as relações raciais brasileiras, muitos dos quais filiados à Associação Brasileira de Pesquisadores Negros (ABPN), que poderiam ter sido consultados. Disponível em: https://www.abpn.org.br/. Acesso em: 14 abr. 2020. 
Ambiente acadêmico brasileiro: branquidade e exclusão de direitos dos estudantes negros Sales Augusto dos Santos

uma episteme ou um modo de ver, interpretar e agir sobre o mundo: o ponto de vista eurocêntrico.

Em março de 2017, quando o CEPE da UFV deliberou que "o estudante [denunciado como fraudador das subcotas étnico-raciais] será considerado não enquadrado na condição de pessoa preta, parda ou indígena quando houver unanimidade entre os integrantes da Comissão", a professora Nilma Gomes, agente das lutas supracitadas, já havia publicado mais de vinte livros, assim como mais de cem artigos em livros e em revistas acadêmicas, nacionais e internacionais, sobre as relações raciais brasileiras e as políticas de ação afirmativa. Não bastasse isso, entre outras atribuições, a doutora Nilma Gomes já havia sido: a) Presidente da Associação Brasileira de Pesquisadores Negros (ABPN), de 2004 a 2006; b) Coordenadora Geral do Programa Ações Afirmativas da UFMG, de 2002 a de 2013; c) membro da Câmara de Educação Básica do Conselho Nacional de Educação (CNE), no período de 2010 a 2014; d) Coordenadora do GT 21 - Educação e Relações Étnico-Raciais, da Associação Nacional de Pós-Graduação e Pesquisa em Educação (ANPED), de 2011 a 2013; e) Reitora Pró-Tempore da Universidade da Integração Internacional da Lusofonia Afro-Brasileira (UNILAB), de 2013 a 2014; f) Secretária de Políticas de Promoção da Igualdade Racial, do governo federal, de janeiro de 2015 a setembro de 2015; e g) Ministra das Mulheres, Igualdade Racial, da Juventude e dos Direitos Humanos, de outubro de 2015 a maio de 2016. ${ }^{31}$

Como se constata, na época, a professora Nilma Gomes tinha conhecimento, experiência e um currículo exemplar, que poucos professores universitários brasileiros têm. Mais do que isso, ela era e ainda é uma autoridade nos estudos e pesquisas sobre políticas de promoção da igualdade racial. Frise-se que a professora Gomes não era uma desconhecida da e na UFV, visto que em 2015 (portanto, antes da deliberação do CEPE, supracitada) ela esteve na universidade, a convite da instituição, para proferir a aula inaugural do ano letivo na UFV, cujo tema foi “Universidade, equidade e diversidade: desafios da promoção da igualdade racial".

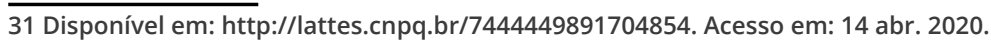


Ambiente acadêmico brasileiro: branquidade e exclusão de direitos dos estudantes negros

Internamente, ou seja, na própria UFV, havia professores e/ ou pesquisadores iniciados no tema das relações raciais, visto que o Departamento de Ciências Sociais (DCS) ministrou um curso de Pós-Graduação lato sensu sobre gestão de políticas públicas em gênero e raça, no período de dezembro de 2009 a dezembro de 2014, que buscava formar profissionais para atuar na elaboração, monitoramento e avaliação de programas e ações relacionadas à temática de gênero e raça (LOPES, 2020). Mais do que isso, um ano antes da reunião do CEPE de 08 março de 2017, havia ingressado um docente no DCS que tinha construído a sua trajetória acadêmica pesquisando, estudando e lecionando os assuntos supracitados. Isto é, este pesquisador possuía extensa publicação sobre políticas de ação afirmativa e as relações raciais brasileiras. Portanto, no DCS da UFV havia docentes que poderiam ter sido consultados sobre o tema deliberado no dia 08 de março de 2017 pelo CEPE.

Por conseguinte, havia docentes/pesquisadores das relações raciais brasileiras de fora da UFV e internos, ou seja, da própria instituição, que poderiam ter sido convidados para discutir, informar, esclarecer questões aparentemente confusas, enfim, assessorar os membros do CEPE, entre outras possibilidades, com vistas à tomada de decisão sobre como poderia ser a forma de ingresso ou não ingresso de estudantes nas subcotas étnico-raciais da instituição, bem como sobre o funcionamento da CVAER, de forma que essa não prejudicasse alguns dos sujeitos de direito das subcotas étnico-raciais, nem possibilitasse o ingresso de estudantes brancos nelas. Porém, como visto ao longo deste artigo, os conselheiros do CEPE não reconheceram ou, caso se queira, desprezaram aqueles docentes, assim como os seus conhecimentos sobre as relações raciais brasileiras e, principalmente, sobre a implementação de políticas de promoção da igualdade racial em universidades públicas.

O menosprezo dos membros do CEPE à produção de conhecimento e/ou às qualidades acadêmico-intelectuais dos negros intelectuais é mais uma evidência que dá suporte à plausibilidade 
Ambiente acadêmico brasileiro: branquidade e exclusão de direitos dos estudantes negros

da nossa hipótese, qual seja, de que a deliberação dos membros desse conselho, do dia 08 de março de 2017, que prejudicou dezenas de estudantes negros, ocorreu em razão da branquidade desses membros.

\section{Considerações finais}

Neste artigo buscamos compreender e, de alguma forma, responder por que os membros do CEPE da UFV, fundamentados no argumento in dubio pro reo, impuseram uma forma de operacionalização à CVAER da universidade que, simultânea e contraditoriamente, impediu o ingresso fraudulento de alguns estudantes brancos nas vagas das subcotas étnico-raciais destinadas aos estudantes pretos, pardos e indígenas, mas também permitiu o ingresso dezenas daqueles estudantes nessas vagas.

A questão, ao ser investigada, nos ajuda a compreender um pouco mais sobre a operacionalização da branquidade no meio acadêmico brasileiro e sobre o racismo estrutural vigente em nosso país. Assim, considerando o racismo à brasileira, duas das características dos programas de pós-graduação brasileiros no que diz respeito às relações raciais, a saber, o confinamento racial e a incrementação do pacto narcísico nesse estágio de formação, considerando o perfil acadêmico dos docentes que participaram da reunião do CEPE de 08 de março de 2017, especialmente de não serem iniciados nos estudos sobre políticas de ação afirmativa, assim como considerando o menosprezo desses docentes aos intelectuais negros, como visto neste artigo, levantamos a hipótese de que foi a branquidade dos conselheiros do CEPE da UFV que levou à tomada da decisão supracitada, que, como se sabe, excluiu dezenas de estudantes negros da universidade e incluiu outras dezenas de estudantes brancos nas vagas destinadas àqueles, como visto ao longo do texto.

Por meio de evidências empíricas e argumentos plausíveis, demonstramos que a branquidade, como um fato social, não só 
Ambiente acadêmico brasileiro: branquidade e exclusão de direitos dos estudantes negros Sales Augusto dos Santos

autorizou os conselheiros do CEPE, como exigiu deles deliberarem sobre um tema sobre o qual eles não tinham conhecimento acadêmico-científico. Mais ainda, a formação monocromática desses conselheiros, assim como o pacto narcísico, um dos traços fundamentais da branquitude, os orientaram no sentido de não convidarem doutores renomados sobre o tema para os assessorarem na tomada de decisão. Frise-se que alguns especialistas sobre o assunto eram conhecidos da e na UFV, como, por exemplo, a renomada professora Nilma Gomes, ex-presidente ABPN.

O não reconhecimento, o desdém e/ou menosprezo dos conselheiros do CEPE da UFV aos conhecimentos dos especialistas sobre políticas de ação afirmativa para população negra poderia ser atribuído às vaidades ou às arrogâncias intelectuais daqueles, tão comum no meio acadêmico. Contudo, não parece ser este o caso, pois tais características não são exclusivas de docentes brancos, visto que acadêmico negros, inclusive muitos que estudam políticas de promoção da igualdade racial, também podem portar (e muitos portam) essas características. Portanto, a questão não se limita a vaidades ou arrogâncias acadêmicas, embora essas também possam fazer parte da resposta à questão que nos propomos a responder neste artigo. Características como essas existem nos docentes e são independentes de sua cor/raça, sexo, orientação sexual, entre tantas outras distinções.

Assim sendo, é plausível sustentar a hipótese de que a deliberação supracitada do CEPE da UFV, tão prejudicial a dezenas de estudantes negros, conforme Santos e Freitas (2019b), também pode ser compreendida e/ou explicada pela branquidade, isto é, tem a ver com socialização racista brasileira e os consequentes privilégios raciais usufruídos pelos brancos em nosso país, conforme se viu ao longo deste artigo.

\section{Referências}

ADORNO, Sérgio. Discriminação racial e justiça criminal em São Paulo. Novos Estudos CEBRAP, n. 43, p. 45-63, novembro 1995. 
Ambiente acadêmico brasileiro: branquidade e exclusão de direitos dos estudantes negros

ALMEIDA, Sílvio Luiz de. O que é racismo estrutural. Belo Horizonte: Letramento, 2018.

BENTO, André. Justiça barra acordo que reintegrou estudante de medicina acusado de fraudar cotas. Dourados News. A fonte de informação, 21 mai. 2020. Disponível em: https://www.douradosnews.com.br/dourados/justica-barra-acordo-que-reintegrou-estudante-de-medicina-acusado-de/1128489/. Acesso em: 21 mai. 2020.

BENTO, André. Reitora reintegra alunos de medicina afastados por suposta fraude em cotas. Dourados News. A fonte de informação, 1 set. 2019. Disponível em: https://www.douradosnews. com.br/dourados/reitora-reintegra-alunos-de-medicina-afastados-por-suposta-fraude-em/1111173/. Acesso em: 21 mai. 2020.

BENTO, Maria Aparecida Silva. "Branquitude e poder - a questão das cotas para negros". In: SANTOS, Sales Augusto dos (Org.).

Ações afirmativas e combate ao racismo nas Américas. Brasília: MEC/SECAD, 2005, p. 165-177.

BENTO, Maria Aparecida Silva. Pactos narcísicos no racismo: branquitude e poder nas organizações empresariais e no poder público. 2002a. Tese (Doutorado em Psicologia) - Instituto de Psicologia/Departamento de Psicologia da Aprendizagem, Universidade de São Paulo, São Paulo, 2002a.

BENTO, Maria Aparecida Silva. Branqueamento e branquitude no Brasil. In: CARONE, Iracy; BENTO, Maria Aparecida Silva (org.). Estudos sobre branquitude e branqueamento no Brasil. Petrópolis: Vozes, 2002b, p. 25-58.

BERNARDINO-COSTA, Joaze; MALDONADO-TORRES, Nelson; GROSFOGUEL, Ramón (org.). Decolonialidade e pensamento afrodiaspórico. Belo Horizonte: Autêntica Editora, 2018.

BOURDIEU, Pierre. Os três estados do capital cultural. In: NOGUEIRA, Maria A.; CATANI, Afrânio (org.). Escritos de educação. Petrópolis: Vozes, 1998. 
Ambiente acadêmico brasileiro: branquidade e exclusão de direitos dos estudantes negros

BRASIL, UFV. ATA/CEPE 529, de 08 março de 2017. Viçosa: UFV, 2017a. Disponível em: http://www.soc.ufv.br/wp-content/uploads/02-ATA-CEPE-529-08.03.17.pdf. Acesso em: 01.jun. 2019.

BRASIL, UFV. ATO n 8/2017/CEPE, de 13 março de 2017. Viçosa: UFV, 2017b. Disponível em: https://www2.dti.ufv.br/noticias/files/ anexos/phpdSOiJz_26847.pdf. Acesso em: 01.jun. 2019.

BRASIL, UFV. Resolução n 1/2000, de 16 março de 2000. Viçosa: UFV, 2000. Disponível em:https://www.novoscursos.ufv.br/orgaos/ufv/soc/www/wp-content/uploads/Regimento-CEPE2.pdf. Acesso em: 07. ago. 2019.

CARDOSO, Lourenço. A branquitude acrítica revisitada e a branquidade. Revista da ABPN, v. 6, n. 13, p. 88-106, 2014.

CARNEIRO, Sueli. Entrevista concedida à revista Caros Amigos. Caros Amigos, São Paulo, ano 4, p. 29, fev. 2000.

CARVALHO, José Jorge de. O confinamento racial do mundo acadêmico brasileiro. Revista USP, n. 68, p. 88-103, dezembro/ fevereiro 2005-2006. https://doi.org/10.11606/issn.2316-9036. v0i68p88-103

CARVALHO, José Jorge de. Inclusão étnica e racial no Brasil: a questão das cotas no ensino superior. São Paulo: Attar, 2005. CERQUEIRA, Daniel; BUENO, Samira (org.). Atlas da Violência 2020. Brasília: IPEA, 2020.

CHAUÍ, Marilena. Cultura e Democracia. São Paulo: Cortez, 1990. CRENSHAW, Kimberlé. Documento para o encontro de especialistas em aspectos da discriminação racial relativos ao gênero. Revista Estudos Feministas, Florianópolis, v. 10, n. 1, p. 171, 2002.

DIVINO, Luiz Flávio Conceição. UFV: docentes negros/as no "mundo" dos homens brancos. TCC (Bacharelado em Ciências Sociais) - Departamento de Ciências Sociais da UFV, 2016. 
Ambiente acadêmico brasileiro: branquidade e exclusão de direitos dos estudantes negros

DURKHEIM, Émile. As regras do método sociológico. São Paulo: Ed. Nacional, 1985.

ENMZ - EXECUTIVA NACIONAL DA MARCHA ZUMBI. Por uma política nacional de combate ao racismo e à desigualdade racial: marcha Zumbi contra o racismo, pela cidadania e vida. Brasília: Cultura Gráfica e Ed., 1996.

FERNANDES, Florestan. 0 negro no mundo dos brancos. São Paulo: Difusão Europeia do Livro, 1972.

FRANKENBERG, Ruth. A miragem de uma branquidade não-marcada. In: WARE, Vron (org.). Branquidade. Identidade branca e multiculturalismo. Rio de Janeiro: Garamond, 2004, p. 307-338.

FRY, Peter et. al. Divisões perigosas: políticas raciais no Brasil contemporâneo. Rio de Janeiro: Editora Civilização Brasileira, 2007.

GROSFOGUEL, Ramón. A estrutura do conhecimento nas universidades ocidentalizadas: racismo/sexismo epistêmico e os quatro genocídios/epistemicídios do longo século XVI. Sociedade e Estado, v. 31, n. 01, p. 25-49, jan./abr. 2016.

IBGE - INSTITUTO BRASILEIRO DE GEOGRAFIA E ESTATÍSTICA. Desigualdades sociais por cor ou raça no Brasil. Rio de Janeiro: IBGE, 2019.

IPEA - INSTITUTO DE PESQUISA ECONÔMICA APLICADA. Retrato das desigualdades de gênero e raça. 4. ed. Brasília: IPEA/ONU Mulheres/SPM/SEPPIR, 2011.

LEAL, Maria do Carmo et al. A cor da dor: iniquidades raciais na atenção pré-natal e ao parto no Brasil. Cadernos de Saúde Pública, v. 33, p. 1-17, 2017. DOI: 10.1590/0102-311X00078816. LOPES, Maria de Fátima. Entrevista concedida (por telefone/ WhatsApp) aos autores. Brasília, 02 de maio de 2020.

MARCONDES, Mariana Mazzini et. al. (org.). Dossiê mulheres negras: retrato das condições de vida das mulheres no Brasil. Brasília: IPEA, 2013. 
Ambiente acadêmico brasileiro: branquidade e exclusão de direitos dos estudantes negros

MIGNOLO, Walter. Desobediência Epistêmica: a opção descolonial e o significado de identidade em política. Cadernos de Letras da UFF, Dossiê: Literatura, língua e identidade, n. 34, p. 287-324, 2008.

MIGNOLO, Walter. Histórias locais/Projeto globais: colonialidade, saberes subalternos e pensamento liminar. Belo Horizonte: Editora UFMG, 2003.

NASCIMENTO, Abdias. Povo negro: a sucessão e a Nova República. Rio de Janeiro: IPEAFRO, 1985.

NASCIMENTO, Abdias (org.). O negro revoltado. Rio de Janeiro: Nova Fronteira, 1982.

NASCIMENTO, Abdias. O quilombismo. Petrópolis: Vozes, 1980. PETRY, Sabrina. Até na hora do parto negra é discriminada. Folha de S. Paulo, São Paulo, 26 mai. 2002. Disponível em: https:// www1.folha.uol.com.br/fsp/cotidian/ff2605200201.htm. Acesso em: 30 mai. 2020.

PIZA, Edith. Branco no Brasil? Ninguém sabe, ninguém viu... In: GUIMARÃES, Antonio Sérgio; HUNTLEY, Lynn (org.). Tirando a máscara: ensaios sobre racismo no Brasil. São Paulo: Paz e Terra, 2000.

QUIJANO, Anibal. Colonialidade do poder, eurocentrismo e América Latina. In: LANDER, Edgardo (org.). A colonialidade do saber: eurocentrismo e ciências sociais. Perspectivas latinoamericanas. Coleccion Sur. Ciudad Autónoma de Buenos Aires, Argentina: CLACSO, 2005, p. 117-142.

RAMOS, Alberto Guerreiro. Introdução crítica à sociologia brasileira. Editora da UFRJ, 1995 [1957].

SANTOS, Sales Augusto dos. Educação: um pensamento negro contemporâneo. Jundiaí: Paco Editorial, 2014.

SANTOS, Sales Augusto dos; FREITAS, Matheus Silva. Fraudes en el sistema de cuotas brasileño: una mirada hacia la remarginal- 
Ambiente acadêmico brasileiro: branquidade e exclusão de direitos dos estudantes negros

ización de las mujeres negras. Revista argentina de sociologia, v. 15, n. 25, p. 142-169, julio-diciembre 2019a.

SANTOS, Sales Augusto dos; FREITAS, Matheus Silva. Comissão de Heteroidentificação Étnico-Racial: averiguação, impedimento e legitimação de fraudes. Revista Liberdades, n. 28, p. 44-61, junho/ dezembro 2019b.

SCHUCMAN, Lia Vainer. Branquitude e poder: revisitando o "medo branco" no século XXI. Revista da ABPN, v. 6, n. 13, p. 88106, 2014.

SOVIK, Liv. Aqui ninguém é branco: hegemonia branca e media no Brasil. In: WARE, Vron (org.). Branquidade. Identidade branca e multiculturalismo. Rio de Janeiro: Garamond, 2004, p. 115-137.

WAISELFISZ, Julio Jacobo. Mapa da violência 2014. Os jovens do Brasil. Brasília: SGPR/SNJ/ Seppir, 2014.

WAISELFISZ, Julio Jacobo. Mapa da Violência 2012: A cor dos homicídios no Brasil. Rio de Janeiro: CEBELA, FLACSO; Brasília: SEPPIR/PR, 2012.

WARE, Vron (org.). Branquidade. Identidade branca e multiculturalismo. Rio de Janeiro: Garamond, 2004.

WEBER, Max. Economía y sociedad. México: Fondo de Cultura Económica, 1964. 